\title{
Scleral changes induced by atropine in chicks as an experimental model of myopia
}

\author{
Patricia Gallego ${ }^{1}$, Carmen Martínez-García ${ }^{1}$, Pablo Pérez-Merino ${ }^{1}$, Lucía Ibares-Frías ${ }^{1}$, Agustín \\ Mayo-Iscar ${ }^{2}$ and Jesús Merayo-Lloves ${ }^{3}$ \\ ${ }^{1}$ Department of Cell Biology, Histology and Pharmacology, School of Medicine, University of Valladolid, ${ }^{2}$ Department of Statistics, School of \\ Medicine, University of Valladolid, Valladolid, and ${ }^{3}$ Fernandez Vega Ophthalmic Research Foundation, Oviedo, Spain
}

Citation information: Gallego P, Martínez-García C, Pérez-Merino P, Ibares-Frías L, Mayo-Iscar A \& Merayo-Lloves J. Scleral changes induced by atropine in chicks as an experimental model of myopia. Ophthalmic Physiol Opt 2012, 32, 478-484. doi: 10.1111/j.1475-1313.2012.00940.x

Keywords: atropine, chicks, myopia, sclera

Correspondence: Patricia Gallego Muñoz E-mail address: patricia.gallego.munoz@uva.es

Received: 11 January 2012; Accepted: 2 August 2012

\begin{abstract}
Purpose: To determine the effects of intravitreal atropine on scleral growth in the form-deprived chick as an experimental model of myopia.

Methods: Five groups of five chicks were studied from day 0-12 post-hatching. One group remained untreated (C), and four were form-deprived by monocular light diffusers to induce myopia. Two groups (RL and A) wore diffusers for 9 days, and the other two groups $(\mathrm{D}$ and $\mathrm{D}+\mathrm{A}$ ) wore diffusers throughout the study. Group D received no further treatment (myopia positive control). Groups $\mathrm{A}$ and $\mathrm{D}+\mathrm{A}$ received intravitreal injections of atropine for days 9-12. Measurements of refractive error and axial length were performed on days 0,9 , and 12 . Sclera changes were assessed in cartilaginous and fibrous layers by histological analysis.

Results: All form-deprived eyes had a myopic refractive error on day 9. All atropine-treated groups were hyperopic on day 12. The effect of atropine was most evident in Group D + A in which diffusers were maintained throughout treatment and changes in refractive error were statistically significant. The observed changes in axial length were in line with the changes in refractive error. The scleral fibrous layer thickness increased, and the sceral cartilaginous layer underwent a slight thinning compared to Group D, the myopia positive control.

Conclusions: If the signals that induce growth remain during atropine treatment, morphological changes in sclera are produced: the scleral fibrous layer thickened, and the sceral cartilaginous layer thinned. These changes resulted in refractive error recovery, and the ocular growth was stopped. The data suggested the atropine was acting throughout the scleral fibrous layer.
\end{abstract}

\section{Introduction}

The process of emmetropisation is based on an active and visually-guided mechanism in the growing eye that achieves a close match of the focal length of cornea and lens to the axial length. When the retinal image is degraded by the absence of a normal visual experience in the early stages of development, the normal course of emmetropisation is compromised, and the eye continues to grow in the axial dimension, resulting in myopia. ${ }^{1}$ Myopia is a very common condition in humans, and it is related to environmental and genetic factors. ${ }^{2,3}$ Since the shape of the eye is defined by the mechanical properties of the sclera, alterations in this layer may be linked to the progression of myopia. ${ }^{4,5}$ Furthermore, it has been suggested that myopia is associated mainly with a longer axial length due to enlargement of the vitreous chamber. ${ }^{6-9}$

During the development of myopia, a retinal-scleral photomechanotransduction pathway mediates the remodelling of the scleral matrix. ${ }^{6-9}$ This leads to a reduced stiffness in the scleral layer associated with sclera thinning and the formation of posterior sclera ectasias. ${ }^{10,11}$ 
The requirement of a clear retinal image for proper emmetropisation has been extensively studied using different mammalian and avian models. Animal models based on form deprivation and optical defocus have been used in the early developmental stages to alter emmetropisation and to induce myopia.,12-16 The chick has been the most common animal model for studying the progression of myopia due to its low cost and fast response to alterations in the visual environment. While there are similarities between the fibrous layer of the chick and that of mammals, the chick sclera also has a cartilaginous layer that is not present in human eyes. ${ }^{4,17,18}$ During the progression of myopia by visual manipulation in the chick model, the cartilaginous and the fibrous layers have opposite effects on eye growth. The posterior cartilaginous layer increases in thickness, while, the fibrous layer thins, as it does in mammals. ${ }^{4}$

Recently, considerable efforts have been made to develop drugs that prevent myopia. Two drugs have been clinically tested for their myopia-preventing effect, atropine and pirenzepine. Atropine is a non-selective muscarinic receptor antagonist ${ }^{19-23}$ and pirenzepine preferentially blocks mammalian M1 and M4 receptors. ${ }^{24-26}$ However, both drugs have ocular and systemic side effects, and the preventative effects on the development of myopia are lost after extended application. ${ }^{19,27}$

Previous studies have explored the effects of atropine in preventing the development of myopia in the chick animal model. ${ }^{20,22,24,26,28}$ The high potency of intravitreal atropine suggests an intraocular target, e.g., the sclera. ${ }^{20,22,25}$ However, the mechanism by which atropine produces its action is still unclear. This is a critical question, as atropine is currently used as an off-label treatment for myopia in children, especially in Southeast Asia.

In this study, we used the form-deprived chick experimental model of myopia to analyse ocular biometric, refractive and morphological changes in the scleral layers. Form deprivation was achieved by a light diffuser, and the effect of atropine was tested in myopic eyes after the diffuser was removed and in eyes that continued to develop myopia.

\section{Materials and methods}

\section{Animals}

Twenty-five male White Leghorn chicks (Gallus gallus domesticus) obtained from a local hatchery (Ibertec, http: Ilwww.ibertec.es) on the same day they hatched, day 0, were used in this study. The animals were cared for following the guidelines of the Association for Research in Vision and Ophthalmology (ARVO) Statement for the Use of Animals in Ophthalmic and Vision Research. The chicks were kept in a large incubator on a 12-h light/12-h dark cycle in the animal facilities of the university. The room tempera- ture was kept at $30^{\circ} \mathrm{C}$ during the first post-hatching week and at $28^{\circ} \mathrm{C}$ thereafter. Water and food were supplied ad libitum.

On day 0 , light diffusers, handmade from frosted plastic foil, were attached to the left eyes as previously described. ${ }^{20}$ The light diffusers had little effect on retinal illumination, but prevented 'form vision'. The right eyes remained untouched as a control.

We conducted a preliminary study to select the lowest dose of atropine that completely blocked the development of myopia in the form-deprived eyes. Atropine sulfate monohydrate (1\%, Colircusí, Alcon Cusí, S.A., www.alcon.es) was dissolved in ringer lactate (RL, B. Braun, www.bbraun.es) to yield final doses of $0,2.5$, 250, 750, and $2500 \mu \mathrm{g}$. The lowest dose that completely suppressed the development of form deprivation myopia was $750 \mu \mathrm{g}$. That dose was selected for the experiments reported here.

From days 9 to 12, a monocular intravitreal injection of the fresh atropine solution $(12.5 \mu \mathrm{L})$ was administered daily with a $0.03 \mathrm{~mm}(30 \mathrm{G}) \times 8 \mathrm{~mm}$ needle. The chicks were anaesthetised by intramuscular injection of ketamine hydrochloride (37.5 mg kg ${ }^{-1}$, Ketolar; Pfizer, http: \|www. pfizer.com) and xylazine hydrochloride (5 $\mathrm{mg} \mathrm{kg}^{-1}$, Rompun; Bayer AG, www.bayer.com). Additionally, topical anaesthesia was provided by application of $0.5 \%$ tetracaine chlorhydrate and $1 \mathrm{mg}$ of oxybuprocaine (Colircusí Anestésico Doble; Alcon Cusí, S.A., www.alcon.es).

The chicks were divided into five different groups of five animals (Table 1). The control group, Group C, received no treatment. The second group, Group D, wore light diffusers for days $0-12$ and had no other treatment. The third group, Group RL, wore the light diffusers for days 0-9, and received intravitreal injections of Ringer's lactate solution $(12.5 \mu \mathrm{L})$ for days 9-12. The fourth group, Group A, wore light diffusers for days 0-9 and were treated with atropine for days 9-12. The fifth group, (Group D + A) wore the diffusers for days 0-12 and were treated with atropine from

Table 1. Groups and treatment protocols

\begin{tabular}{lll}
\hline Groups & $\begin{array}{l}\text { Duration of diffuser wear } \\
\text { (days) }\end{array}$ & Treatment (days 9-12) \\
\hline C & - & - \\
D & 12 & - \\
RL & 9 & Ringer lactate \\
A & 9 & Atropine \\
A + D & 12 & Atropine \\
\hline
\end{tabular}

C: Untreated animals. D: Group treated with diffusers throughout the study and untreated. RL: Group treated with diffusers until day 9 and treated with ringer lactate from day 9 to 12. A: Group treated with diffusers until day 9 and treated with atropine from day 9 to 12. A + D: Group treated with diffusers throughout the study and treated with atropine from day 9 to $12 . n=5$ for each group. 
days 9-12. The aim of injecting atropine after removal of the diffusers on day 9 (Group A) was to determine if atropine enhanced the rate of the normal recovery process. The RL group, in which Ringer's lactate was injected from day 9, served as a control to determine if the vehicle itself had an effect on the rate of recovery.

\section{Refraction and axial length}

On days 0,9 , and 12 , refraction measurements were made on the unanaesthetised chicks. The refractive state was evaluated with an automated eccentric infrared (IR) photorefractor. ${ }^{3,29-31}$ Afterwards, axial length was measured under topical anaesthesia with a modified ultrasound biometer (Allergan Humphrey Mod. 826, www.allergan.com) as previously described. ${ }^{32,33}$

\section{Tissue processing and light microscopy}

Under anaesthesia, the chicks were killed on day 12 with an overdose of intraperitoneal sodium pentobarbital (Dolethal, register number: 0737-ESP, www.vetoquinol.com), and the ocular globes were enucleated. All of the eyes were dissected, and the external orbital tissue was removed. Each eye was divided into anterior and posterior hemispheres. The posterior hemispheres were fixed with buffered formalin $10 \%$ for $24 \mathrm{~h}$, washed in $0.1 \mathrm{~m}$ phosphate buffered solution, and embedded in paraffin wax. Sections $(7 \mu \mathrm{m})$ were stained with hematoxylin-eosin (H-E). The sections were examined under a light microscope (BX41; Olympus, www. olympus.com), and photomicrographs were obtained with an Olympus DP20 Digital Camera (Olympus, www. olympus.com). The scleral thickness was measured with Soft Cell ${ }^{\mathrm{A}}$ Imaging Software for Life Science Microscopy (Olympus, www.olympus.com) in three different areas per layer and per sample.

\section{Cell proliferation}

One hour before euthanasia, we injected 5-bromo-2'deoxyuridine (intramuscular, $5 \mathrm{ml} \mathrm{kg}{ }^{-1}$ of BrdU-B5002; Sigma, www.sigmaaldrich.com) to label newly synthesised DNA. Sections of labelled tissue, prepared as described above, were deparaffinised and treated with $2 \mathrm{~N} \mathrm{HCL}$ for $1 \mathrm{~h}$ at $37^{\circ} \mathrm{C}$. After rinsing with tris-buffered saline (TBS), the samples were incubated with mouse monoclonal IgG anti-BrdU (1:20 dilution in TBS, M0744; Dako, www.dako. com) for $30 \mathrm{~min}$ at room temperature. The secondary antibody was fluorescein goat anti-mouse IgG (F2761; Molecular Probes, www.invitrogen.com). Sections were examined under an Axiophot fluorescence-incorporated microscope (426 510-9901-000; Carl Zeiss, www.zeiss.com) and the photomicrographs were captured using the Axio CAM HRc
10-33 VDC Zeiss (Carl Zeiss, www.zeiss.com). Labelled cells were counted at $\times 20$ magnification.

\section{Statistics}

Means \pm standard deviations were calculated for each of the variables. $T$-tests were used to determine the statistical significance of changes in each group on days 9 and 12. The differences between groups were evaluated with the Scheffe multiple comparison procedure. This test allowed for the control of type I error in a global way. The level of statistical significance was set at $p<0.05$.

\section{Results}

There were no significant differences in refraction or axial length between the untreated contralateral right eyes and untreated left eyes of Group C. For the purpose of this study, only the left eyes of Group C animals were used as controls.

\section{Refractive error}

Before the light diffusers were placed, all chicks exhibited moderate hyperopic errors (Table 2). On day 9, animals with light diffusers (Groups D, A, D + A, and RL) had a collective myopic refractive error of $-2.69 \pm 0.32$ dioptres (D). On day 12, the treated eyes of Groups A and D + A were hyperopic $(+1.11 \pm 0.21 \mathrm{D}$ and $+1.46 \pm 0.41$ respectively). At the same time, the treated eyes of Group RL had a level of hyperopia similar to that of Group C (Table 2).

\section{Axial length}

Control eyes (Group C) increased in axial length from $7.41 \pm 0.47 \mathrm{~mm}$ on day 0 to $7.92 \pm 0.26 \mathrm{~mm}$ on day 9 (Table 2). For all of the groups with light diffusers, the axial length on day 9 was greater than for the controls. By day 12, the axial lengths were similar for all groups except Group D, $9.14 \pm 0.31 \mathrm{~mm}$, which was slightly greater than the others. The differences found between days 9 and 12 in each group were significant only for Group A, which changed from $8.53 \pm 0.06$ to $8.08 \pm 0.10 \mathrm{~mm}(p=0.02)$.

\section{Morphological changes in the scleral layers}

Figure 1 shows representative changes in the thickness of the scleral layers in each group. For Group RL, the thickness of the cartilaginous layer, $44.10 \pm 5.31 \mu \mathrm{m}$, was significantly thinner than the same layer in Group D (Table 3). The fibrous layer of Group RL eyes was slightly, but not significantly, thicker than the fibrous layer of the Group D eyes. The cartilaginous layer of Groups A and D $+A$, 
Table 2. Data of ocular refractive error (RE) in dioptres (D) and axial length (AL) in millimeters $(\mathrm{mm})$ collected on days 0,9 and 12

\begin{tabular}{|c|c|c|c|c|}
\hline Groups & Measurements & Day 0 & Day 9 & Day 12 \\
\hline \multirow[t]{2}{*}{ C } & $\mathrm{RE}(\mathrm{D})$ & $+7.64 \pm 1.35$ & $+2.27 \pm 0.30^{*}$ & $+2.85 \pm 0.45$ \\
\hline & $\mathrm{AL}(\mathrm{mm})$ & $7.41 \pm 0.47$ & $7.92 \pm 0.26$ & $8.03 \pm 0.34$ \\
\hline \multirow[t]{2}{*}{ D } & $\mathrm{RE}(\mathrm{D})$ & $+7.54 \pm 1.84$ & $-2.24 \pm 0.51$ & $-3.78 \pm 0.86$ \\
\hline & $\mathrm{AL}(\mathrm{mm})$ & $7.70 \pm 0.26$ & $8.61 \pm 0.43$ & $9.14 \pm 0.31$ \\
\hline \multirow[t]{2}{*}{$R L$} & $\mathrm{RE}(\mathrm{D})$ & $+6.13 \pm 0.24$ & $-2.73 \pm 0.07^{*}$ & $+2.18 \pm 0.52$ \\
\hline & $\mathrm{AL}(\mathrm{mm})$ & $6.92 \pm 0.24$ & $8.60 \pm 0.44$ & $8.56 \pm 0.62$ \\
\hline \multirow[t]{2}{*}{ A } & $\mathrm{RE}(\mathrm{D})$ & $+6.98 \pm 1.80$ & $-3.02 \pm 0.28^{*}$ & $+1.11 \pm 0.21$ \\
\hline & $\mathrm{AL}(\mathrm{mm})$ & $7.88 \pm 0.70$ & $8.53 \pm 0.06^{*}$ & $8.08 \pm 0.10$ \\
\hline \multirow[t]{2}{*}{$D+A$} & $\mathrm{RE}(\mathrm{D})$ & $+7.21 \pm 1.09$ & $-2.80 \pm 0.99 *$ & $+1.46 \pm 0.41$ \\
\hline & $\mathrm{AL}(\mathrm{mm})$ & $7.37 \pm 0.42$ & $8.80 \pm 0.14$ & $8.75 \pm 0.17$ \\
\hline
\end{tabular}

*Statistically significant differences $(p<0.05)$ found in the changes between days 9 and 12 in the same group. C: Untreated animals. D: Group treated with diffusers throughout the study and untreated. RL: Group treated with diffusers until day 9 and treated with ringer lactate from day 9 to 12. A: Group treated with diffusers until day 9 and treated with atropine from day 9 to 12. D + A: Group treated with diffusers throughout the study and treated with atropine from day 9 to 12 .
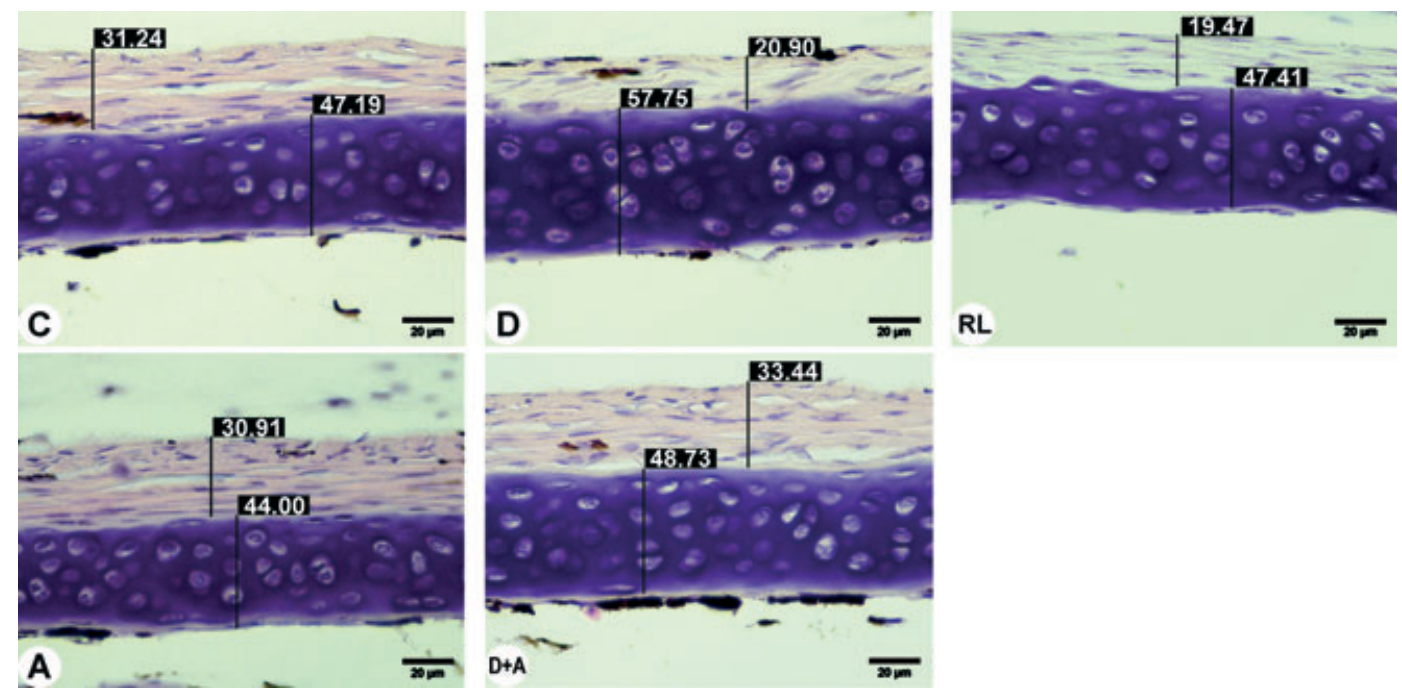

Figure 1. Photomicrographs of the scleral sections stained with Hematoxylin-Eosin (H\&E) in different experimental groups on day 12. C: untreated animals; D: group treated with diffusers throughout the study and untreated; RL: group treated with diffusers until day 9 and treated with ringer lactate from day 9 to 12; A: group treated with diffusers until day 9 and treated with atropine from day 9 to 12; D+A: group treated with diffusers throughout the study and treated with atropine from day 9 to 12 . The numbers in each layer denote the thickness in micrometers ( $\mu \mathrm{m})$. Scale bar is $20 \mu \mathrm{m}$. Magnification $\times 400$.

$42.61 \pm 2.53 \mu \mathrm{m}$ and $47.95 \pm 5.78 \mu \mathrm{m}$ respectively, were both significantly thinner than in the Group D eyes. In contrast, the fibrous layers of Groups $\mathrm{A}$ and $\mathrm{D}+\mathrm{A}$, $30.76 \pm 3.66$ and $26.34 \pm 3.69 \mu \mathrm{m}$ respectively, were thicker than in the Group D eyes.

\section{Cell proliferation in the scleral layers}

The number of BrdU-labelled cells in the cartilaginous layer of Group C was $18.60 \pm 5.9$ (Table 3). For Groups D and $\mathrm{RL}$, the number of labelled cells was slightly higher than the controls, and for Groups $\mathrm{A}$ and $\mathrm{D}+\mathrm{A}$, the atropine- injected groups, the number of labelled cells was slightly lower. However, none of the differences in labelling were significant. For the fibrous layer, in Group $\mathrm{C}$ the number of BrdU-labeled cells was $11.40 \pm 2.30$ (Table 3). For all other groups, there were slightly fewer labelled cells, but again, the differences were not statistically significant.

\section{Discussion}

Previous studies have described the anatomical changes in chick eyes during the development of form deprivationinduced myopia, ${ }^{3,20,33-38}$ as well as the inhibitory effects of 
Table 3. Scleral fibrous and cartilaginous layer thicknesses ( $\mu \mathrm{m})$ and BrdU-labeling ( $n=$ number of BrdU-labeled cells)

\begin{tabular}{llcl}
\hline Groups & Measurements & Fibrous Layer & $\begin{array}{l}\text { Cartilaginous } \\
\text { Layer }\end{array}$ \\
\hline C & Thickness $(\mu \mathrm{m})$ & $32.38 \pm 6.05^{*}$ & $48.06 \pm 4.80^{* *}$ \\
& BrdU positive cells $(n)$ & $11.40 \pm 2.30$ & $18.60 \pm 5.94$ \\
D & Thickness $(\mu \mathrm{m})$ & $17.58 \pm 4.84$ & $56.88 \pm 15.91$ \\
& BrdU positive cells $(n)$ & $8.66 \pm 2.08$ & $23.66 \pm 6.35$ \\
RL & Thickness $(\mu \mathrm{m})$ & $19.58 \pm 6.15$ & $44.10 \pm 5.31^{* *}$ \\
& BrdU positive cells $(n)$ & $9.66 \pm 2.05$ & $22.33 \pm 2.08$ \\
A & Thickness $(\mu \mathrm{m})$ & $30.76 \pm 3.66^{*}$ & $42.61 \pm 2.53^{* *}$ \\
& BrdU positive cells $(n)$ & $10.66 \pm 1.52$ & $13.33 \pm 1.15$ \\
D + A & Thickness $(\mu \mathrm{m})$ & $26.34 \pm 3.69^{*}$ & $47.95 \pm 5.78^{* *}$ \\
& BrdU positive cells $(n)$ & $9.75 \pm 0.95$ & $15.75 \pm 1.50$ \\
\hline
\end{tabular}

*Statistically significant differences with respect to the $D$ and RL groups $(p<0.05)$ in the fibrous layer thickness.

**Statistically significant differences with respect to the D group $(p<0.05)$ in the cartilaginous layer thickness.

C: untreated animals. D: Group treated with diffusers throughout the study and untreated. RL: Group treated with diffusers until day 9 and treated with ringer lactate from day 9 to 12 . A: Group treated with diffusers until day 9 and treated with atropine from day 9 to 12. D + A: Group treated with diffusers throughout the study and treated with atropine from day 9 to 12 .

intravitreal atropine treatment. ${ }^{20,23}$ However, none of these studies have reported the morphological changes in the sclera due to the atropine treatment.

Myopia induced by wearing diffusers is highly variable among individual chicks, ranging from $-20.3 \pm 1.0$ to $-6.1 \pm 0.3 \mathrm{D}^{39,40}$ In the present study, control eyes showed moderate hyperopic values throughout the experiment. Before the atropine treatment started at day 9 , chicks wearing diffusers were about $5 \mathrm{D}$ more myopic than chicks with normal vision. The variation between studies is related to the amount of light diffusion produced by the diffuser. ${ }^{41}$ For our study, resting refraction was objectively analysed by IR-photoretinoscopy, which took into account the most hyperopic value at which the retinal reflex was reversed. ${ }^{42}$ Furthermore, myopia induction in chicks may be affected by the large amplitude of accommodation. ${ }^{33}$ The axial length changes between Groups C and D were similar to those reported in previous studies. ${ }^{33}$

The recovery process of the different groups was evaluated by analysing the refraction and axial length measurements. By day 12, the refractive state and axial length of the RL group were similar to Group C. Group A, which received the intravitreal atropine injections, had a faster rate of recovery than Group RL, which received only the Ringer's lactate injection. However, Group D + A, which wore the diffuser for 12 days and received the atropine injection from days 9-12, showed the most interesting results. In contrast to the Group D chicks, the refractive state of Group D + A reached hyperopic values, and the eye stopped growing. These data suggest that the progression of myopia in chicks might be delayed with atropine treatment, consistent with other reports. ${ }^{20,22,26,43}$

Because the scleral layer shows ultrastructural and biomechanical changes in high myopia, ${ }^{6-9}$ this layer might represent one of the targets for therapeutic manipulation of myopia. Several studies showed opposite modulation of growth in the scleral fibrous and cartilaginous layers. ${ }^{4,34,44-47}$ In the present study, the scleral thickness of both layers was analysed to evaluate the morphological changes of different groups. Consistent with previous studies, the study found that the cartilaginous layer was thicker in Group D animals and the fibrous layer was thinner than the normal eyes in Group C. In addition, the scleral changes after atropine treatment were the opposite of the changes in Group D. The thickness of both scleral layers in Group A, which had the diffuser for 9 days and then atropine treatment until day 12, was similar to those in Group C on day 12. For Group D + A, the signal that induced eye growth remained constant throughout the study because the chicks wore light diffusers. Thus, the real effect of atropine treatment may be best observed in this group.

The thickness of the cartilaginous layer was similar in Groups D and D + A. However, treatment with atropine in Groups A and D + A restored the thickness of the posterior fibrous layer to the control level in Group C. This suggests that the effect of atropine treatment is located in this area of the sclera.

There is a significant volume of literature regarding changes in scleral structure during the development of experimental myopia, the localisation of muscarinic cholinergic receptors within the eye, the effects of muscarinic agents on scleral remodelling and on the possible sites of action of such compounds. ${ }^{22,48-50}$ Lind et al. ${ }^{51}$ demonstrated that cellular proliferation and extracellular matrix production in the cartilaginous sclera are inhibited by muscarinic antagonists, including atropine, through what appears to be either an M1 or M4 receptor pathway. This work was further supported by the studies of Wang et al. ${ }^{52}$ and Troung et al. ${ }^{53}$ that demonstrated pirenzepine-induced reductions of glycosaminoglycan levels in the cartilaginous sclera, but not in the fibrous sclera. Such work suggests that atropine inhibits cellular proliferation and extracellular matrix production within the cartilaginous layer, but not within the fibrous layer of the chick sclera.

The biometric and refractive measurements carried out in our study and the histological results demonstrated morphological changes in the posterior scleral layers after atropine treatment, specifically in the fibrous layer, in which the thickness increased. These changes resulted in the recovery of refractive error and the cessation of ocular growth. This work suggests that the effects of atropine on myopia are largely due to its effect on the sclera, and 
therefore, the changes produced by atropine treatment in the fibrous layer may delay the progression of myopia.

Despite these results, more studies are necessary to understand how and where atropine affects the development of myopia. The present study has some limitations. First, it was carried out in chicks as the experimental model; thus comparable studies in mammals are required to determine if they behave similarly with respect to the development of myopia. Another limitation is the fast rate at which myopia occurs in post-hatched animals. It would be useful to analyse the effects of atropine in advanced stages to mimic the development of myopia in humans.

\section{Acknowledgements}

The authors acknowledge funding in part from the PROFIT CIT-300 100-2007-50 grant, Spanish Ministry of Science and Innovation. We would also like to thank Roberto Cantalapiedra Rodríguez for his technical assistance with the histopathology. This work was presented in part as a poster at the annual meeting of the Association for Research in Vision and Ophthalmology, ARVO, Fort Lauderdale, FL, USA, May 2009.

\section{Conflict of interest}

The authors report no conflicts of interest. The authors alone are responsible for the content and writing of the paper.

\section{References}

1. Wildsoet CF. Active emmetropization - evidence for its existence and ramifications for clinical practice. Ophthalmic Physiol Opt 1997; 17: 279-290.

2. Schaeffel F \& Howland HC. Myopia. Vision Res 1995; 35: 1135-1139.

3. Schaeffel F \& Howland HC. Properties of the feedback loops controlling eye growth and refractive state in the chicken. Vision Res 1991; 31: 717-734.

4. Rada JA, Shelton S \& Norton TT. The sclera and myopia. Exp Eye Res 2006; 82: 185-200.

5. Tano Y. Pathologic myopia: where are we now? Am J Ophthalmol 2002; 134: 645-660.

6. Gottlieb MD, Fugate-Wentzek LA \& Wallman J. Different visual deprivations produce different ametropias and different eye shapes. Invest Ophthalmol Vis Sci 1987; 28: 1225-1235.

7. McBrien NA, Jobling AI, Truong HT, Cottriall CL \& Gentle A. Expression of muscarinic receptor subtypes in tree shrew ocular tissues and their regulation during the development of myopia. Mol Vis 2009; 15: 464-475.

8. Rada JA, Perry CA, Slover ML \& Achen VR. Gelatinase A and TIMP-2 expression in the fibrous sclera of myopic and recovering chick eyes. Invest Ophthalmol Vis Sci 1999; 40: 3091-3099.

9. Rada JA \& Palmer L. Choroidal regulation of scleral glycosaminoglycan synthesis during recovery from induced myopia. Invest Ophthalmol Vis Sci 2007; 48: 2957-2966.

10. Curtin BJ. The posterior staphyloma of pathologic myopia. Trans Am Ophthalmol Soc 1977; 75: 67-86.

11. Curtin BJ. Pathologic myopia. Acta Ophthalmol Suppl 1988; 185: 105-106.

12. Hayes BP, Fitzke FW, Hodos W \& Holden AL. A morphological analysis of experimental myopia in young chickens. Invest Ophthalmol Vis Sci 1986; 27: 981-991.

13. Troilo D \& Wallman J. The regulation of eye growth and refractive state: an experimental study of emmetropization. Vision Res 1991; 31: 1237-1250.

14. Wallman J \& Adams JI. Developmental aspects of experimental myopia in chicks: susceptibility, recovery and relation to emmetropization. Vision Res 1987; 27: 1139-1163.

15. Diether S \& Schaeffel F. Local changes in eye growth induced by imposed local refractive error despite active accommodation. Vision Res 1997; 37: 659-668.

16. Schaeffel F, Glasser A \& Howland H. Accommodation, refractive error and eye growth in chickens. Vision Res 1988; 28: 639-657.

17. McBrien NA \& Gentle A. Role of the sclera in the development and pathological complications of myopia. Prog Retin Eye Res 2003; 22: 307-338.

18. Rada JA, Achen VR, Perry CA \& Fox PW. Proteoglycans in the Human Sclera Evidence for the presence of aggrecan. Invest Ophthalmol Vis Sci 1997; 38: 1740-1751.

19. Chua WH, Balakrishnan V, Chan $\mathrm{YH}$ et al. Atropine for the treatment of childhood myopia. Ophthalmology 2006; 113: 2285-2291.

20. Diether S, Schaeffel F, Lambrou GN, Fritsch C \& Trendelenburg A. Effects of intravitreally and intraperitoneally injected atropine on two types of experimental myopia in chicken. Exp Eye Res 2007; 84: 266-274.

21. Diether S \& Schaeffel F. Long-term changes in retinal contrast sensitivity in chicks from frosted occluders and drugs: relations to myopia? Vision Res 1999; 39: 2499-2510.

22. McBrien NA, Moghaddam HO \& Reeder AP. Atropine reduces experimental myopia and eye enlargement via a nonaccommodative mechanism. Invest Ophthalmol Vis Sci 1993; 34: 205-215.

23. Schmid KL \& Wildsoet CF. Inhibitory effects of apomorphine and atropine and their combination on myopia in chicks. Optom Vis Sci 2004; 81: 137-147.

24. Metlapally R \& McBrien NA. The effect of pirenzepine on positive and negative lens-induced refractive error and ocular growth in chicks. Invest Ophthalmol Vis Sci 2010; 51: 5438-5444.

25. Cottriall CL, McBrien NA, Annies R \& Leech EM. Prevention of form-deprivation myopia with pirenzepine: a study of drug delivery and distribution. Ophthalmic Physiol Opt 1999; 27: 327-335. 
26. Stone RA, Lin T \& Laties AM. Muscarinic antagonist effects on experimental chick myopia. Exp Eye Res 1991; 52: 755-758.

27. Bartlett JD, Niemann K, Houde B, Allred T, Edmondson MJ \& Crockett RS. A tolerability study of pirenzepine ophthalmic gel in myopic children. J Ocul Pharmacol Ther 2003; 19: 271-279.

28. Schwahn HN, Kaymak H \& Schaeffel F. Effects of atropine on refractive development, dopamine release, and slow retinal potentials in the chick. Vis Neurosci 2000; 17: 165-176.

29. Schaeffel F, Wilhelm H \& Zrenner E. Inter-individual variability in the dynamics of natural accommodation in humans: relation to age and refractive errors. J Physiol 1993; 461: 301-320.

30. Schaeffel F, Farkas L \& Howland HC. Infrared photoretinoscope. Appl Opt 1987; 26: 1505-1509.

31. Schaeffel F, Hagel G, Eikermann J \& Collett T. Lower-field myopia and astigmatism in amphibians and chickens. J Opt Soc Am A Opt Image Sci Vis 1994; 11: 487-495.

32. Schaeffel F \& Howland HC. Corneal accommodation in chick and pigeon. J Comp Physiol A 1987; 160: 375-384.

33. García de la Cera E, Rodríguez G \& Marcos S. Longitudinal changes of optical aberrations in normal and form-deprived myopic chick eyes. Vision Res 2006; 46: 579-589.

34. Kusakari T, Sato T \& Tokoro T. Visual deprivation stimulates the exchange of the fibrous sclera into the cartilaginous sclera in chicks. Exp Eye Res 2001; 73: 533-546.

35. Wallman J, Turkel J \& Trachtman JN. Extreme myopia produced by modest change in early visual experience. Science 1978; 201: 1249-1251.

36. Wallman J, Adams JI \& Trachtman JN. The eyes of young chickens grow toward emmetropia. Invest Ophthalmol Vis Sci 1981; 20: 557-561.

37. Schaeffel F, Troilo D, Wallman J \& Howland HC. Developing eyes that lack accommodation grow to compensate for imposed defocus. Vis Neurosci 1990; 4: 177-183.

38. Rada JA, Thoft RA \& Hassell JR. Increased aggrecan (cartilage proteoglycan) in the sclera of myopic chicks production. Dev Biol 1991; 147: 303-312.

39. Phillips JR, Khalaj M \& McBrien NA. Induced myopia associated with increased scleral creep in chick and tree shrew eyes. Invest Ophthalmol Vis Sci 2000; 41: 2028-2034.

40. Vessey KA, Cottriall CL \& McBrien NA. Muscarinic receptor protein expression in the ocular tissues of the chick during normal and myopic eye development. Brain Res Dev Brain Res 2002; 135: 79-86.
41. Bartmann M \& Schaeffel F. A simple mechanism for emmetropization without cues from accommodation or colour. Vision Res 1994; 34: 873-876.

42. Li T, Troilo D, Glasser A \& Howland HC. Constant light produces severe corneal flattening and hyperopia in chickens. Vision Res 1995; 35: 1203-1209.

43. Kusakari T, Sato T \& Tokoro T. Regional scleral changes in form-deprivation myopia in chicks. Exp Eye Res 1997; 64: 465-476.

44. Marzani D \& Wallman J. Growth of the two layers of the chick sclera is modulated reciprocally by visual conditions. Invest Ophthalmol Vis Sci 1997; 38: 1726-1739.

45. Gottlieb MD, Joshi HB \& Nickla DL. Scleral changes in chicks with form-deprivation myopia. Curr Eye Res 1990; 9: 1157-1165.

46. Schippert R, Brand C, Schaeffel F \& Feldkaemper MP. Changes in scleral MMP-2, TIMP-2 and TGFbeta-2 mRNA expression after imposed myopic and hyperopic defocus in chickens. Exp Eye Res 2006; 82: 710-719.

47. Nietgen GW, Schmidt J, Hesse L, Hönemann CW \& Durieux ME. Muscarinic receptor functioning and distribution in the eye: molecular basis and implications for clinical diagnosis and therapy. Eye (Lond) 1999; 13: 285-300.

48. Fisher AJ, Miethke P, Morgan IG \& Stell WK. Cholinergic amacrine cells are not required for the progression and atropine-mediated suppression of form deprivation myopia. Brain Res 1998; 794: 48-60.

49. Bitzer M, Kovacs B, Feldkaemper M \& Schaeffel F. Effects of muscarinic antagonists on ZENK expression in the chicken retina. Exp Eye Res 2006; 83: 379-388.

50. Ashby R, McCarthy CS, Maleszka R, Megaw P \& Morgan IG. A muscarinic cholinergic antagonist and a dopamine agonist rapidly increase ZENK mRNA expression in the formdeprived chicken retina. Exp Eye Res 2007; 85: 15-22.

51. Lind GJ, Chew SJ, Marzani D \& Wallman J. Muscarinic acetylcholine receptor antagonists inhibit chick scleral chondrocytes. Invest Ophthalmol Vis Sci 1998; 39: 2217-2231.

52. Wang IJ, Shih YF, Tseng HS, Huang SH, Lin LL \& Hung PT. The effect of intravitreal injection of atropine on the proliferation of scleral chondrocytes in vivo. J Ocul Pharmacol Ther 1998; 14: 337-343.

53. Troung HT, Cottriall CL, Gentle A \& McBrien NA. Pirenzepine affects scleral metabolic changes in myopia through a non-toxic mechanism. Exp Eye Res 2002; 74: 103-111. 